\title{
Epstein-Barr Virus Transcription in Nasopharyngeal Carcinoma
}

\author{
NANCY RAAB-TRAUB, ${ }^{*}$ RACHEL HOOD, CZAU-SIUNG YANG, $\dagger$ BERCH HENRY II, AND \\ JOSEPH S. PAGANO \\ Departments of Microbiology and Immunology and Medicine and Cancer Research Center, University of \\ North Carolina, Chapel Hill, North Carolina 27514
}

Received 18 April 1983/Accepted 13 September 1983

\begin{abstract}
Sequences which encode Epstein-Barr virus (EBV) RNA in nasopharyngeal carcinoma (NPC) tissue have been identified. We utilized human biopsy material directly as well as NPC grown in nude mice. Total RNA was extracted from the tumor material and separated into polyadenylated and nonpolyadenylated fractions by oligodeoxythymidylate-cellulose chromatography. This material was used as template to construct ${ }^{32} \mathrm{P}$-labeled cDNA. The labeled cDNAs were hybridized to Southern blots of recombinant EBV DNA fragments. Three of the biopsies, F, 49, and 55, contained polyadenylated RNA homologous to the EBV $B a m \mathrm{HI}$ fragments $\mathrm{V}$ and $\mathrm{K}$, and EcoRI-DIJhet. These same fragments encode the most abundant polyribosomal RNAs in latently infected lymphoblastoid cell lines. The sequences which encoded nonpolyadenylated RNA in NPC tumor 49 were more extensive and included BamHI fragments C, V, B, E, and K, and EcoRI fragments DIJhet, E, F, and $\mathrm{G} 1$, a result that indicates selective polyadenylation in EBV RNA processing. A fourth biopsy, NPC tumor 18, contained polyadenylated RNA homologous to the Bam HI fragments $\mathrm{H}, \mathrm{B}, \mathrm{K}, \mathrm{Y}, \mathrm{B} 1, \mathrm{I} 1$, and $\mathrm{A}$ and EcoRI fragments $\mathrm{F}$ and G2. A similar pattern of transcription was identified in three tumor specimens from nude mice, 4,5 , and 8 . Transformation of lymphocytes did not ociur after cocultivation in vitro with explants from these nude mice tumors. This transcriptional pattern may represent an activated state of the EBV genome, formerly not detected in tumor tissue, which is analogous to the state of abortive infection identified in induced in vitro cell systems.
\end{abstract}

The Epstein-Barr virus (EBV) is the etiological agent of infectious mononucleosis, a benign lymphoproliferative disease (16), and is associated with African Burkitt's lymphoma, a monoclonal B lymphoblastoid malignancy (10), and nasopharyngeal carcinoma (NCP), a tumor arising from the squamous epithelium of the nasopharynx (19). Although EBV is thought to be lymphotrophic, in NPC tissue EBV DNA is detected in the malignant epithelial cells and not within the lymphocytes which heavily infiltrate the carcinomatous tissue (38). Biochemical analyses of the role of EBV in NPC have been hampered because the malignant epithelial cells cannot be cultivated in vitro, and pathological tissue can only be obtained by biopsy. However, these tumors can be grown in nude mice, which eliminates the infiltrating human lymphoid elements. These epithelial tumors when cultivated in the nude mice retain EBV DNA and the EBV nuclear antigen $(25,33)$.

+ Present address: National Taiwan University, Taipei, Taiwan.
Each of the pathological processes associated with EBV has a distinct pattern of antibody response to viral antigens (17). Patients with NPC have elevated immunoglobulin G (IgG) and IgA titers $(15,17)$ to the viral capsid antigen $(14)$ and early antigen (EA) (18) and to an EBVassociated DNase (2). These titers increase with tumor burden and can be used as indicators for prognosis (19). In addition, rises in EA titers precede the onset of NPC by 1 to 2 years (8). Although EA and viral capsid antigen cannot be detected in latently infected, growth-transformed lymphocytes and are only detected in cells which are abortively or productively infected, the serological profiles of patients with NPC and Burkitt's lymphoma suggest that an activated state of viral expression, perhaps analogous to an abortive infection, may be an important part of the malignant process. Moreover, in NPC, expression of EA and viral capsid antigen most likely occurs in tissues which stimulate $\operatorname{IgA}$ production.

Analyses of EBV transcription have been conducted in latently, abortively, and produc- 
tively infected lymphoblastoid cell lines. In latently infected lymphocytes, three relatively abundant polyadenylated RNAs encoded by BamHI V, X, and H, BamHI-K, and EcoRIDhet are transcribed $(23,35)$. Several lines of evidence indicate that the transcript from BamHI-K encodes a component of EBV nuclear antigen $(20,32)$.

EBV transcription in abortive infection has been studied in latently infected Raji cells which can be induced to a more permissive infection with halogenated nucleosides, sodium butyrate, or phorbol esters (24). EA can be detected in these cells. After induction, transcription from Bam HI fragment $\mathrm{H}$ greatly increases, and additional sequences encode polyadenylated RNA, including BamHI fragments $\mathrm{A}, \mathrm{B}, \mathrm{E}$, and $\mathrm{M}$.

In permissively infected cells, the complexity of polyadenylated RNA is approximately that of the single-stranded EBV genome. More than 50 EBV RNAs have been identified in B95-8 cells (21) and in HR-1 cells (37), which have been induced to a high level of permissive infection by treatment with the tumor promoter 12-O-tetradecanoyl-phorbol-13-acetate. Some of these RNAs are classified as persistent early RNAs based on their continued synthesis in the presence of phosphonoacetic acid (21). These RNAs have been shown to encode components of EA in in vitro translations (22). Many of these persistent early RNAs are encoded by the additional sequences that are transcribed in Raji cells after induction. From these various in vitro observations, it appears that abortive infection may be characterized by the synthesis of a subset of early viral replicative functions.

Based on such in vitro data, it should then be possible to ascertain the state of viral expression at the level of RNA by determining sequence complexity and transcriptional patterns directly in NPC - an important step forward toward understanding the virus-cell relations and the different antibody responses in the EBV-associated diseases. In the course of this work, we uncovered an EBV transcriptional pattern in NPC tissues, which we term "activated," that up to now had only been seen in vitro with the experimental manipulations mentioned earlier. We also analyzed EBV transcription in NPC cultivated in nude mice.

\section{MATERIALS AND METHODS}

Tumor material. NPC tissue documented histopathologically by G. Pearson and colleagues, Mayo Clinic, Rochester, Minn., and A. Huang and colleagues, Duke University, Durham, N.C., was used for this work. Specimens, NPC F, C, 49, and 55 were designated as World Health Organization (WHO) NPC class WHO 3 , and specimen 18 was WHO class 1 . The NPC specimens passaged in nude mice were all WHO class 3.

Isolation of RNA. All glassware used in the isolation and selection of RNA was treated with $0.2 \%$ diethyl pyrocarbonate for $2 \mathrm{~h}$ and then autoclaved or baked overnight at $250^{\circ} \mathrm{C}$. The tumor samples were homogenized in a Tissumizer (Tekmar Inc., Cincinnati, Ohio) in a solution consisting of $4 \mathrm{M}$ guanidine thiocyanate (Tridom, Inc., Hauppage, N.Y.), 0.5\% Sarkosyl, 0.1 M 2-mercaptoethanol, 0.1\% antifoam A (Sigma Chemical Co., St. Louis, Mo.), and $25 \mathrm{mM}$ sodium citrate, $\mathrm{pH}$ 7.0 (3). The RNA was purified through a cesium chloride step gradient (30).

Polyadenylated and nonpolyadenylated RNAs were separated by oligodeoxythymidylate-cellulose chromatography (1) (type 3; Collaborative Research, Waltham, Mass.).

Identification of viral DNA which encodes RNA in nasopharyngeal tumor tissue. To identify the EBV sequences which are transcribed in the tumor tissue, cDNA to polyadenylated and nonpolyadenylated RNA was synthesized with avian myeloblastosis virus reverse transcriptase (J. Beard, Life Sciences, St. Petersburg, Fla.). The reaction mixture contained: 2 to $30 \mu \mathrm{g}$ of RNA; $200 \mu \mathrm{Ci}$ of [ $\left.{ }^{32} \mathrm{P}\right] \mathrm{dCTP}$ (New England Nuclear Corp., Boston, Mass.); $500 \mu \mathrm{M}$ dATP, dGTP, and dTTP (P-L Biochemicals, Milwaukee, Wis.); $30 \mathrm{mM}$ 2-mercaptoethanol; $10 \mathrm{mM} \mathrm{MgCl} ; \mathbf{0}$.01\% Nonidet P-40; $6 \mu \mathrm{g}$ of actinomycin $\mathrm{D}$ per $\mathrm{ml}$; and $30 \mathrm{U}$ of reverse transcriptase in a $100-\mu$ l reaction volume. The reaction was primed with 0.1 absorbance units at $260 \mathrm{~nm}$ of oligodeoxythymidine (P-L Biochemicals) to provide a further selection for polyadenylated RNA. Regions of the EBV genome which may be transcribed but not polyadenylated were identified by synthesis of cDNA, primed with $200 \mu \mathrm{g}$ of random oligodeoxynucleotides per $\mathrm{ml}$ (33), to the RNA obtained from the effluent of the oligodeoxythymidine-cellulose column.

The ${ }^{32}$ P-labeled cDNAs were then hybridized to Southern blots (31) of recombinant DNA EcoRI fragments of EBV W91 DNA (27). In addition, blots of recombinant DNA of the BamHI fragments $\mathrm{V}, \mathrm{K}, \mathrm{R}$, B1, I1, W1, C, and H (4) were included in the hybridizations to verify possible hybridization to regions of particular interest. The BamHI fragments V, K, and $\mathrm{H}$ are transcribed in latently infected lymphocyte cell lines (24). Bam HI-C encodes two polyadenylated RNAs of very low abundance and two nonpolyadenylated RNAs (35). The fragments $B 1, I 1$, and $W 1$ contain the sequences deleted from the B95 strain $(26,27)$ and are thought to encode, in part, the most abundant RNAs in Burkitt tumor tissue (6).

Preparation of Southern blots and hybridization conditions. The recombinant DNAs of the three largest EcoRI fragments, A, B, and C, were digested with $E c o R I$ and $B a m H I$, the recombinant DNAs of the EcoRI fragments DIJhet, E, F, G1, G2, and $\mathrm{H}$ were digested with EcoRI, and the recombinant DNAs of the $B a m \mathrm{HI}$ fragments were digested with $B a m H I$. The fragments were separated by electrophoresis through a $0.5 \%$ agarose gel and transferred to nitrocellulose (31). The blots of each fragment were cut into duplicate strips. One strip of each set was hybridized to EBV HR1 virion DNA labeled with $\left[{ }^{32} \mathrm{P}\right] \mathrm{dCTP}$ by nick translation (29). This step determined the position of the EBV fragment(s) on the blot and provided a comparison of the relative strength of each blot. 
The nitrocellulose blots of the EBV fragments were pretreated for $4 \mathrm{~h}$ at $72^{\circ} \mathrm{C}$ in hybridization buffer consisting of $10 \times$ Denhardt reagent (7), $100 \mu \mathrm{g}$ of singlestranded calf-thymus DNA per $\mathrm{ml}, 100 \mu \mathrm{g}$ of polyadenylate (Sigma) per ml, $0.2 \%$ sodium dodecyl sulfate and $6 \times \mathrm{SSC}(1 \times \mathrm{SSC}$ is $0.15 \mathrm{M} \mathrm{NaCl}$ pus $0.015 \mathrm{M}$ sodium citrate). The labeled cDNA was hybridized to the pretreated blots in fresh hybridization buffer at $72^{\circ} \mathrm{C}$ for $18 \mathrm{~h}$. The blots were washed at $72^{\circ} \mathrm{C}$ in $0.2 \%$ sodium dodecyl sulfate in SSC in decreasing concentrations to $0.1 \times \mathrm{SSC}$.

\section{RESULTS}

Identification of the EBV fragments transcribed in NPC obtained by biopsy. (i) NPC specimens $\mathbf{F}$ and $\mathbf{C}$. Biopsies $\mathrm{F}$ and $\mathrm{C}$ were each less than $0.05 \mathrm{~g}$. Therefore, the ${ }^{32}$ P-labeled cDNA was synthesized from the total RNA prepared from these biopsies and primed with oligodeoxythymidine as the only selection for polyadenylated sequences. The hybridizations with cDNA to RNA from specimen F, cDNA to RNA from specimen $C$, and ${ }^{32}$ P-labeled HR1 DNA to the blots of the recombinant EBV DNA fragments are shown in Fig. 1. The hybridization with EBV HR1 DNA to each fragment is positioned on the left and is aligned with the cDNA hybridization. The strongest hybridization with the cDNAs prepared from specimens $\mathrm{F}$ and $\mathrm{C}$ was to the BamHI V fragment, which is generated by a single cut within the large internal repeated sequence of the EBV genome. This hybridization was detected both on the blot of the EcoRI/BamHI digestion of the EcoRI-A fragment and on the blot of the $B a m H I V$ fragment. Hybridization to undigested Bam HI$\mathrm{V}$ recombinant DNA was present on the blot of this fragment. Hybridization was also detected to the $B a m \mathrm{HI}$ fragments $\mathrm{X}$ and $\mathrm{C}$, which are adjacent to Bam HI-V, each of which contains a part of the internal repeated sequence. The cDNA to RNA from specimen NPC F also hybridized to Bam HI-K within EcoRI-B and weakly to the clone of the fused-termini $E c o$ RI fragment DIJhet. The regions of EBV that were transcribed in these two tumors are represented in the EBV genome map in Fig. 7a.

(ii) NPC specimens 55 and 49. Hybridization with cDNA to the polyadenylated RNA from NPC specimens 55 and 49 was detected to the Bam HI fragments V and $\mathrm{K}$ and EcoRI-DIJhet (Fig. 2a and b). The intensity of hybridization to the EcoRI DIJhet fragment was much stronger in these specimens compared to the hybridizations with the cDNAs prepared from NPC specimens $\mathrm{F}$ and $\mathrm{C}$, which might reflect differences in the relative abundance of transcription from this fragment.

The oligodeoxynucleotide-primed cDNA to the nonpolyadenylated RNA from biopsy 49 hybridized to the $B a m \mathrm{HI}$ fragments $\mathrm{C}, \mathrm{H}$, and V within EcoRI-A; to BamHI fragments B, E, and $\mathrm{K}$ within $E c o \mathrm{RI}-\mathrm{B}$; and to $E c o \mathrm{RI}$ fragments D, $\mathrm{E}, \mathrm{F}$, and $\mathrm{G} 1$ (Fig. 2c). These results indicate that there was good selection for polyadenylated sequences in the previous hybridization and that a subset of the total EBV RNAs which are transcribed in NPC 49 is polyadenylated. Similar results with RNA from EBV-infected lymphoblastoid cell cultures suggests selective processing of EBV viral RNA $(23,24)$.

(iii) NPC specimen 18. Hybridization with cDNA to the polyadenylated RNA from specimen 18 was detected to BamHI-H within EcoRIA; to $B a m H I$ fragments $B$ and $\mathrm{K}$ and faintly to fragments $\mathrm{E}$ and $\mathrm{Y}$ within EcoRI-B; to BamHI fragments B1, I1, V1, and A within EcoRI-C; to EcoRI-DIJhet; and weakly to EcoRI fragments $\mathrm{F}$ and G2 (Fig. 3a). The Bam HI fragments $\mathrm{H}$ and $\mathrm{B} 1$ contain homologous duplicated sequences $(5$, 27). Therefore, cDNA from RNA transcribed from either of the duplicated sequences will hybridize to $\mathrm{B} 1$ and $\mathrm{H}$. Hybridization with the cDNA to the nonpolyadenylated RNA was detected to Bam HI fragments C, H, B1, and V and to EcoRI fragments DIJhet, F, and E (Fig. 3b). In summary, although sequences from $B a m H I-V$ can be detected in the nonpolyadenylated RNA, no hybridization was detected to Bam HI-V with the cDNA from the polyadenylated RNA from NPC 18. Moreover, hybridization was readily detected to the BamHI-H fragment from which transcription greatly increases in iododeoxyuridine (IUdR)-induced Raji cells (24) and which encodes an abundant 2.5-kilobase persistent early RNA in a productive infection (21). Hybridization was also detected to additional sequences, many of which were transcribed after induction of Raji cells with IUdR.

Identification of the $\mathrm{EBV}$ sequences transcribed in NPC grown in nude mice. NPC, like other tissues of epithelial origin, can be cultivated only with difficulty, if at all, in vitro. Therefore, we turned to specimens of NPC that had been cultivated in nude mice. The three original NPC specimens were from three Taiwanese patients. Five tumors derived by cultivation of these three specimens in nude mice were analyzed. Three of the tumors are different passages of the same original NPC. One of the tumors is a lymphoblastoid tumor which resulted from the inoculation of a lymphoblastoid cell line established during attempts to cultivate NPC tissue, but it is not epithelial tissue.

(i) NM 4, 5, and 8. Nude mouse tumors (NMs) 4,5 , and 8 are different passages of the same original NPC specimen. NM 4 had been passaged in nude mice 38 times, NM 5 had been passaged 39 times, and NM 8 had been passaged 13 times, cultivated in vitro once, and then passaged an additional 20 times. Cocultivation 


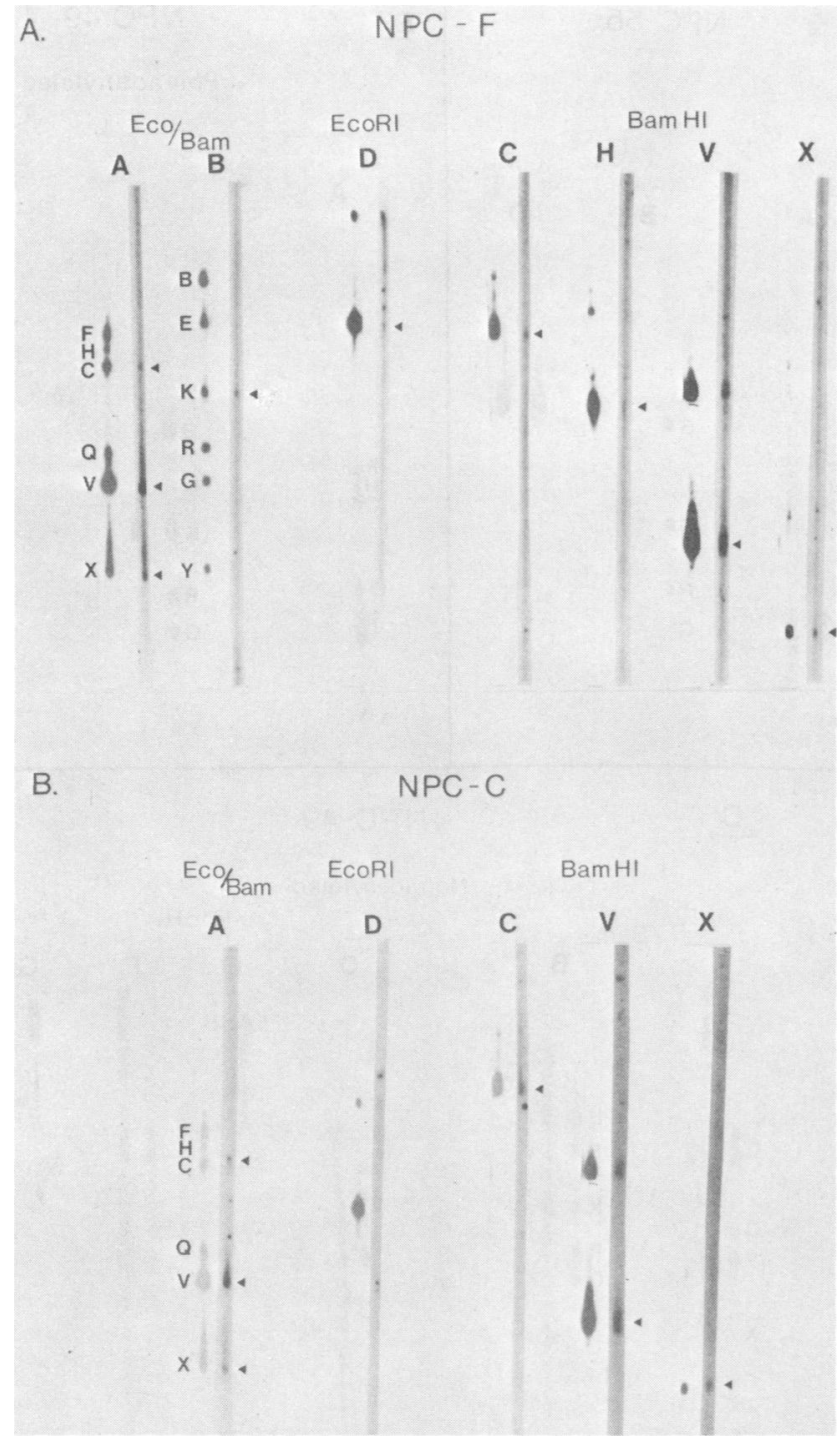

FIG. 1. Identification of the EBV sequences which encode polyadenylated RNA in NPC biopsy specimens $F$ and $C$. ${ }^{32} \mathrm{P}$-labeled cDNAs synthesized to the polyadenylated RNA from tumor $F$ (panel $A$ ) and to the polyadenylated RNA from tumor C (panel B) were hybridized to duplicate strips of blots of restriction enzyme fragments of EBV. The EcoRI fragments, A, B, and C were digested with EcoRI and Bam HI. The Bam HI fragments within each of the $E c o$ RI fragments are indicated at the left. A duplicate strip of each blot, which was hybridized to ${ }^{32} \mathrm{P}$-labeled HR1 viral DNA, is shown to the left of the cDNA hybridization. The arrows indicate hybridization with the cDNA probe.

of in vitro explants of these tumors with lymphocytes did not result in lymphocyte transformation.

The, transcriptional patterns of these tumor passage levels were very similar. The cDNAs prepared from the polyadenylated RNA from NMs 4, 5, and 8 (Fig. 4a, b, and c) hybridized to Bam HI-H within EcoRI-A; to Bam HI fragments $\mathrm{B}, \mathrm{K}$, and $\mathrm{Y}$ within EcoRI-B; to BamHI-B1 within EcoRI-C; and to EcoRI fragments D, E, $F, G 2$, and $H$. The cDNA from NMs 4 and 5 also hybridized to Bam HI fragments I1, V1, and A within EcoRI-C. The bacterial clones containing the EcoRI fragments E, G1, G2, and $\mathrm{H}$ also contain EcoRI-C to which hybridization can be detected with the cDNA from NMs 4 and 5. The arrows denote the positions of E, G1, G2, and $\mathrm{H}$.

The cDNA from the nonpolyadenylated RNA from NM 8 hybridized to Bam HI fragments F, $\mathrm{H}$, and $\mathrm{V}$ within EcoRI-A; to BamHI fragments $\mathrm{B}, \mathrm{E}$, and $\mathrm{K}$ within EcoRI-B; to BamHI frag- 


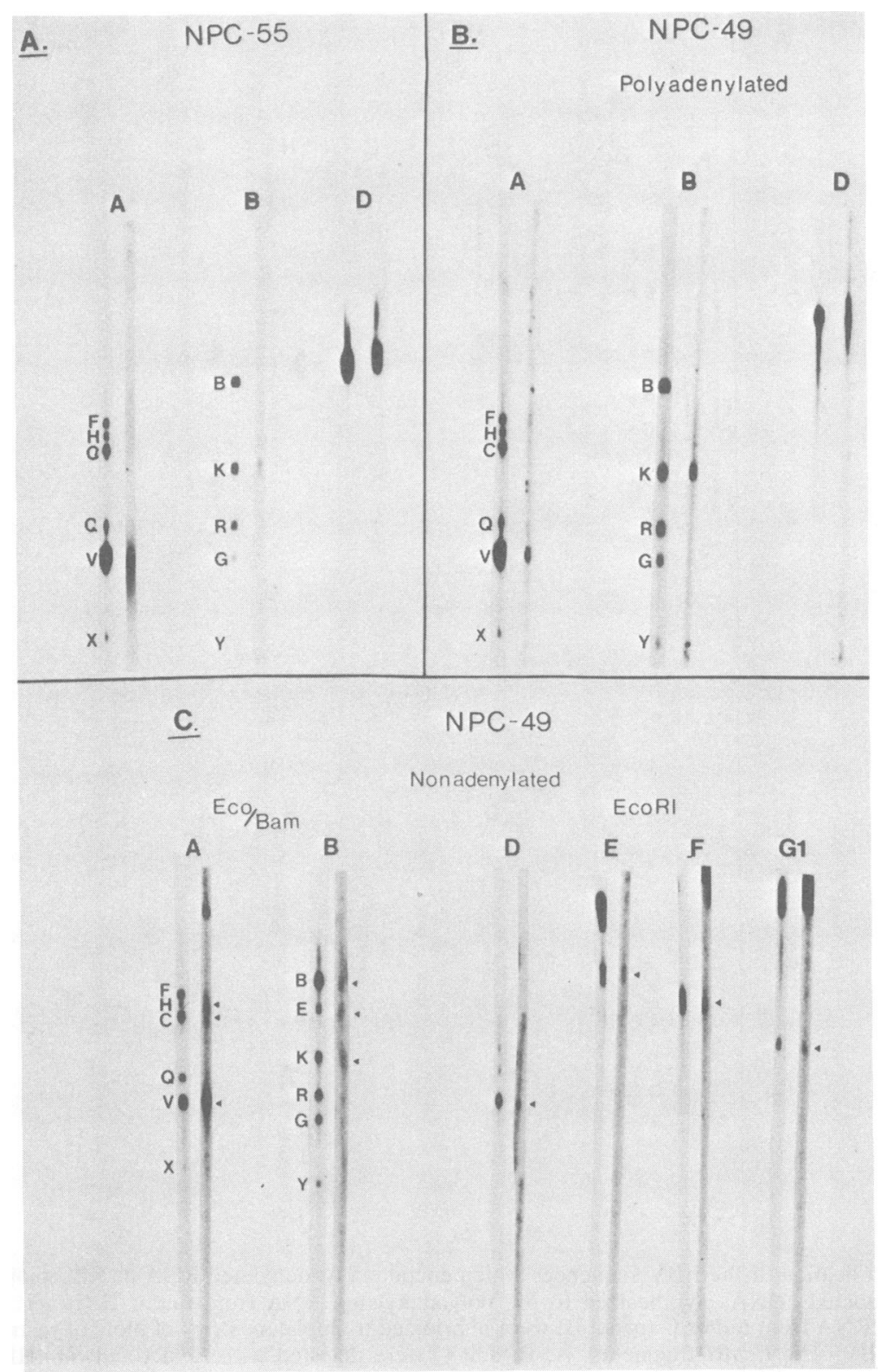

FIG. 2. EBV transcription in NPC biopsy specimens 55 and 49 . The hybridization with ${ }^{32} \mathrm{P}$-labeled $\mathrm{cDNAs}$ to polyadenylated RNA from NPC 55 (A) and polyadenylated (B) and nonpolyadenylated (C) RNA from NPC 49 are shown in the right-hand strip of each fragment and are indicated with arrows. The left strip was hybridized to ${ }^{32}$ P-labeled HR1 viral DNA.

ments B1, I1, and A within EcoRI-C; and to EcoRI fragments D, E, and F (Fig. 4d). These results indicate that RNA processing through selective adenylation is retained in the NPC tissue grown in nude mice.

(ii) NM 1. NM 1 was passaged in nude mice 38 times. Unlike the other NMs transformation of lymphocytes occurred after cocultivation with cells from this tumor, which indicates the presence of infectious virus. The cDNA to the polyadenylated RNA hydridized to all of the BamHI fragments within EcoRI-B; to BamHI fragments B1. I1, V1, W, and A within EcoRI-C; and to EcoRI fragments D, E, F, G1, G2, and $\mathrm{H}$ (Fig. 5). Within EcoRI-A, abundant transcription from $\mathrm{Bam} \mathrm{HI}$ fragments $\mathrm{H}$ and $\mathrm{F}$ was detect- 


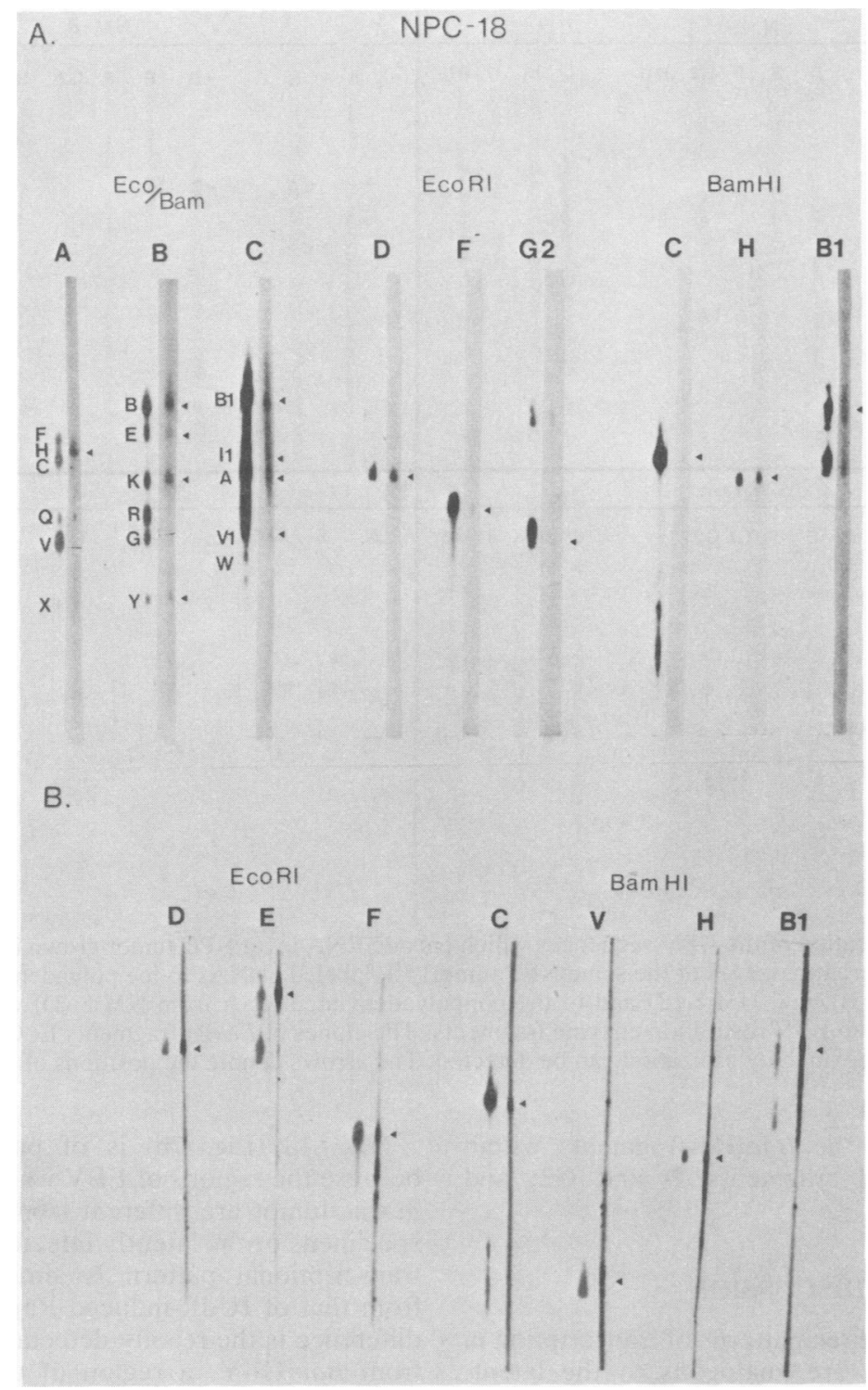

FIG. 3. EBV sequences which encode RNA in NPC 18. Hybridization with cDNAs to the polyadenylated RNA (A) and nonpolyadenylated RNA (B) to restriction enzyme fragments of EBV are shown in the right strip of each blot. The arrows indicate hybridization with the cDNA probe. Hybridization with ${ }^{32} \mathrm{P}$-labeled HR1 viral DNA is presented on the left. The BamHI-B1 clone contains a subpopulation of deleted fragments to which hybridization is also detected. The EcoRI-G2 clone also contains EcoRI-C, to which hybridization can be detected. The arrow denotes the position of $\mathrm{G} 2$.

ed. The pattern of relative abundance indicated by these hybridization results is similar to that found in a productively infected cell line. This is the only sample from which we have detected strong hybridization to BamHI-F, which encodes 11 RNAs in a productive infection (21).

(iii) NM 3. NM 3 is the 31 st passage in nude mice of a lymphoblastoid tumor which resulted from the inoculation of a lymphoblastoid cell line established from NPC tissue. The cDNA to the polyadenylated RNA from this tumor hybridized very strongly to $\mathrm{BamHI}-\mathrm{H}$ in addition to BamHI fragments C, V, E, K, and B1 and EcoRI-Dhet (Fig. 6). Hybridization with the cDNA to the nonpolyadenylated RNA detected Bam HI fragments $\mathrm{C}, \mathrm{V}, \mathrm{H}, \mathrm{X}$, and $\mathrm{F}$ within 


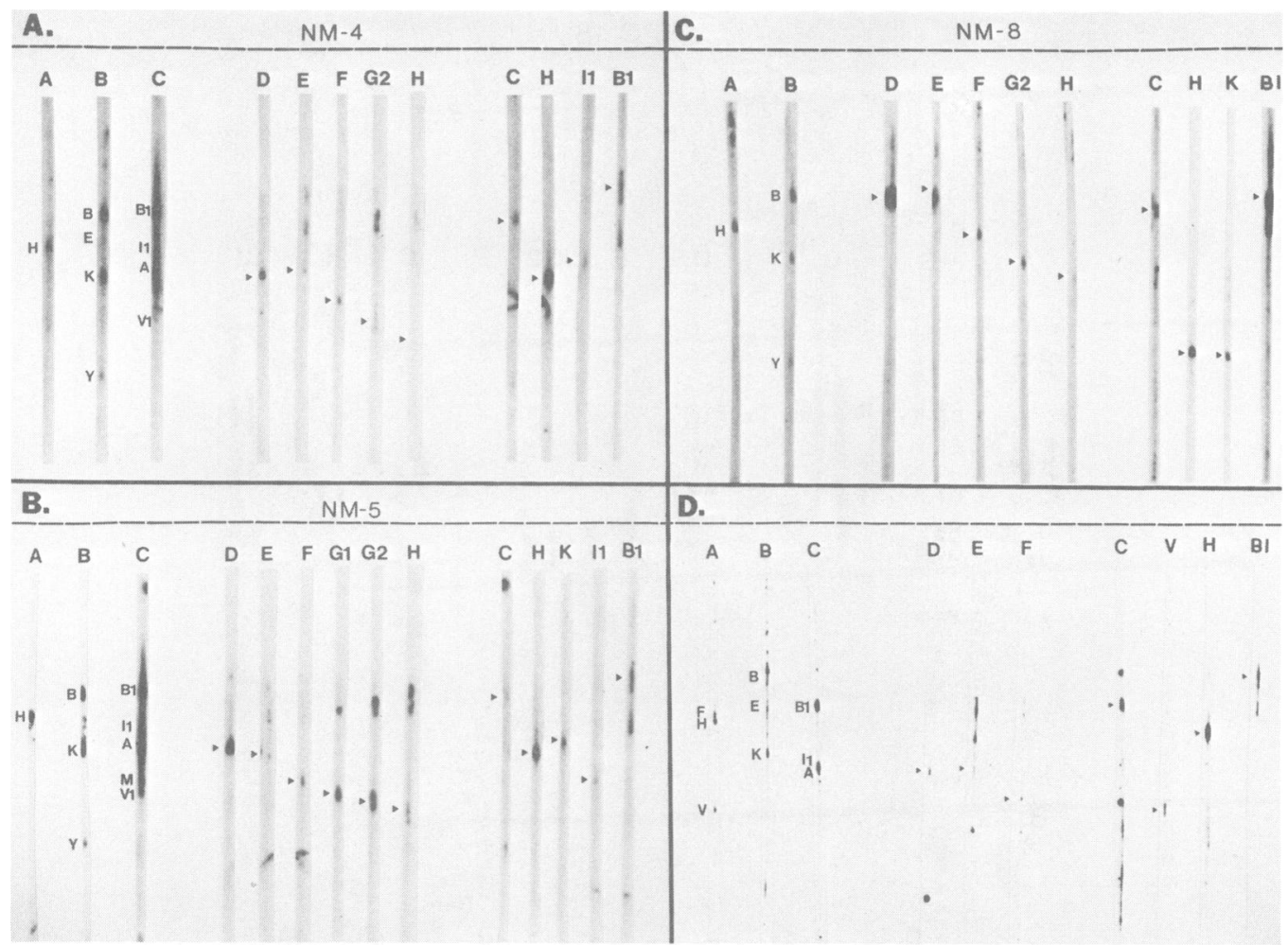

FIG. 4. Identification of the EBV sequences which encode RNA in an NPC tumor grown in nude mice. NMs 4,5 , and 8 are different passages of the same NPC tumor. ${ }^{32}$ P-labeled cDNAs to the polyadenylated RNAs from NM 4 (A), NM 5 (B), and NM 8 (C) and to the nonpolyadenylated RNA from NM 8 (D) were hybridized to duplicate blots of the EBV restriction enzyme fragments. The clones of EcoRI fragments E, G1, G2, and H also contain EcoRI-C to which hybridization can be detected. The arrows denote the positions of E, G1, G2, and H.

EcoRI-A; all of the BamHI fragments within EcoRI-B; EcoRI fragments D and G2; and BamHI-B1.

\section{DISCUSSION}

We identified three patterns of transcription in NPC tissue that are analogous to the latent, abortive, and productive infections identified in latently infected and induced lymphoblastoid cell cultures. To present and contrast the NPC transcriptional patterns best, we grouped them according to pattern and compared them with the corresponding pattern in the EBV lymphoblastoid cell lines. In Fig. 7a, the transcriptional patterns in NPC tissues F, C, 49, and 55 and in the lymphoblastoid tumor grown in nude mice, NM 3, are compared with that of a latently infected cell line (23). The patterns of expression in these tissues are quite similar. Whether the apparent differences in the relative abundance of transcription from particular fragments in the NPC material represent fluctuations in transcription or reflect differences in preservation of template RNA is at this point unknown.
NPC 18 (Fig. 7b) is of particular interest because the regions of EBV which encode RNA in this tumor are different from the other NPC specimens or the latently infected cell lines. The transcriptional pattern is similar yet distinct from that of IUdR-induced Raji cells (24). One difference is the readily detectable transcription from BamHI-Y, a region of the genome that does not encode RNA in latent or IUdR-induced Raji cells but does generate five RNAs, two of which are early, in a productive infection (21). The other obvious difference is the lack of polyadenylated RNA from BamHI-V. Transcription from this fragment is present in Raji cells and is characteristic of latent infection. However, this transcription persists after induction of Raji cells with IUdR. This may be the result of incomplete induction, and the resultant transcriptional pattern may be a composite of the RNAs expressed in latently infected and induced cells. One perspective of the transcriptional pattern in NPC 18 is that it represents a state of abortive infection not simulated by any of the in vitro systems. This finding also suggests that in vivo there may be a transition from 


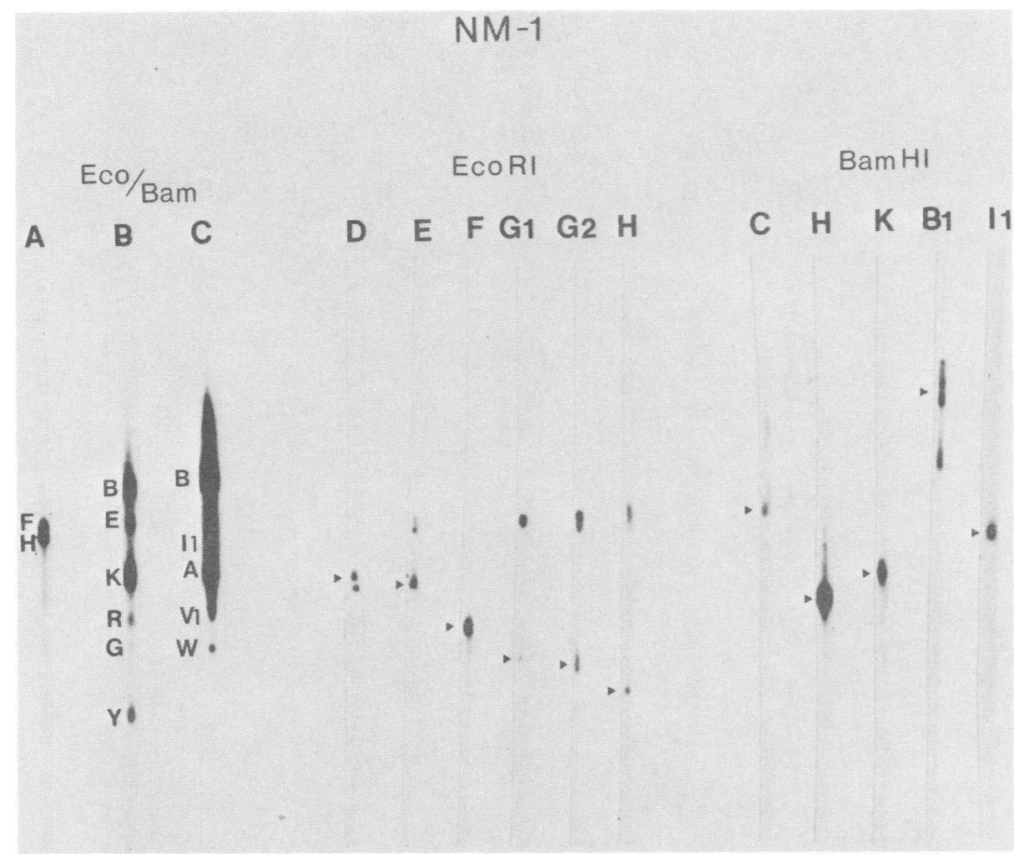

FIG. 5. Identification of the EBV sequences which encode RNA in an NPC grown in nude mice which produces infectious virus.

latent infection to an intermediate state of activated transcription. Such transitions, in some way tied to the course of the disease, may explain the different levels of EBV antibody response detected in patients with NPC.

As it is known that NPC tumor tissue grown in nude mice can produce virus $(11,34)$, the EBV transcription in these tumors may represent an artificial derepression of the genome. The effect of this derepression is quite different in the epithelial tumors, NMs 4, 5, 8, and 1, compared with the lymphoblastoid tumor NM 3. The lymphoblastoid tumor retains a restricted pattern of expression, with the most abundant transcription encoded by Bam HI fragments $\mathrm{V}$ and $\mathrm{H}$ and EcoRI-D. The strong hybridization to Bam HI-H probably reflects some activation and may be due to the abundant 2.5-kilobase early replicative RNA encoded by this fragment in a productive infection (21). In contrast, the epithelial tumors grown in nude mice do not contain polyadenylated RNA from BamHI-V and contain transcripts from other additional regions of the EBV genome. The similarity of the transcriptional patterns for NMs 4, 5, and 8 to that of NPC 18 is striking, with the most abundant transcription encoded by $B a m \mathrm{HI}$ fragments $\mathrm{H}$, B, K, Y, B1, I1, and A. Moreover, comparison of the transcriptional patterns for NMs 4, 5, and 8 , or NPC 18 with that in NM 1 , which is apparently producing virus, reveals several differences between a productive infection and the state of activation in NMs 4, 5, and 8. The sequence complexity of RNA is greatest in NM 1 and includes, in addition to all the sequences transcribed in NMs 4, 5, and 8, abundant transcription from BamHI-F and all of the sequences within EcoRI-B.

The activated state of EBV in the NMs and in NPC 18 is not entirely surprising in that whenever EBV has been introduced into nonlymphoid host cells, either by microinjection (12), transfection (13), or receptor implantation (36), the early antigen has been expressed but not EBV nuclear antigen. It is clear from the data presented here that latent, abortive, and productive infections can occur in epithelial cells. However, essential for the maintenance of latency in epithelial cells may be the presence of EBVreactive $\mathrm{T}$ lymphocytes. Therefore, the loss of the infiltrating lymphocytes during the growth of the tumor tissue in nude mice might promote an activated state of viral expression.

NPCs are classified into three histopathological subtypes by the WHO, which differ in the extent of differentiation of the malignant epithelial cell and the degree of lymphocyte infiltration. The undifferentiated carcinomas, class WHO 3, which are heavily infiltrated with lymphocytes, are clearly associated with EBV, since most patients have elevated EBV antibody titers. The association of EBV with the most differentiated NPC, class WHO 1 , is not as consistent, since patients usually do not have 
A.

A.

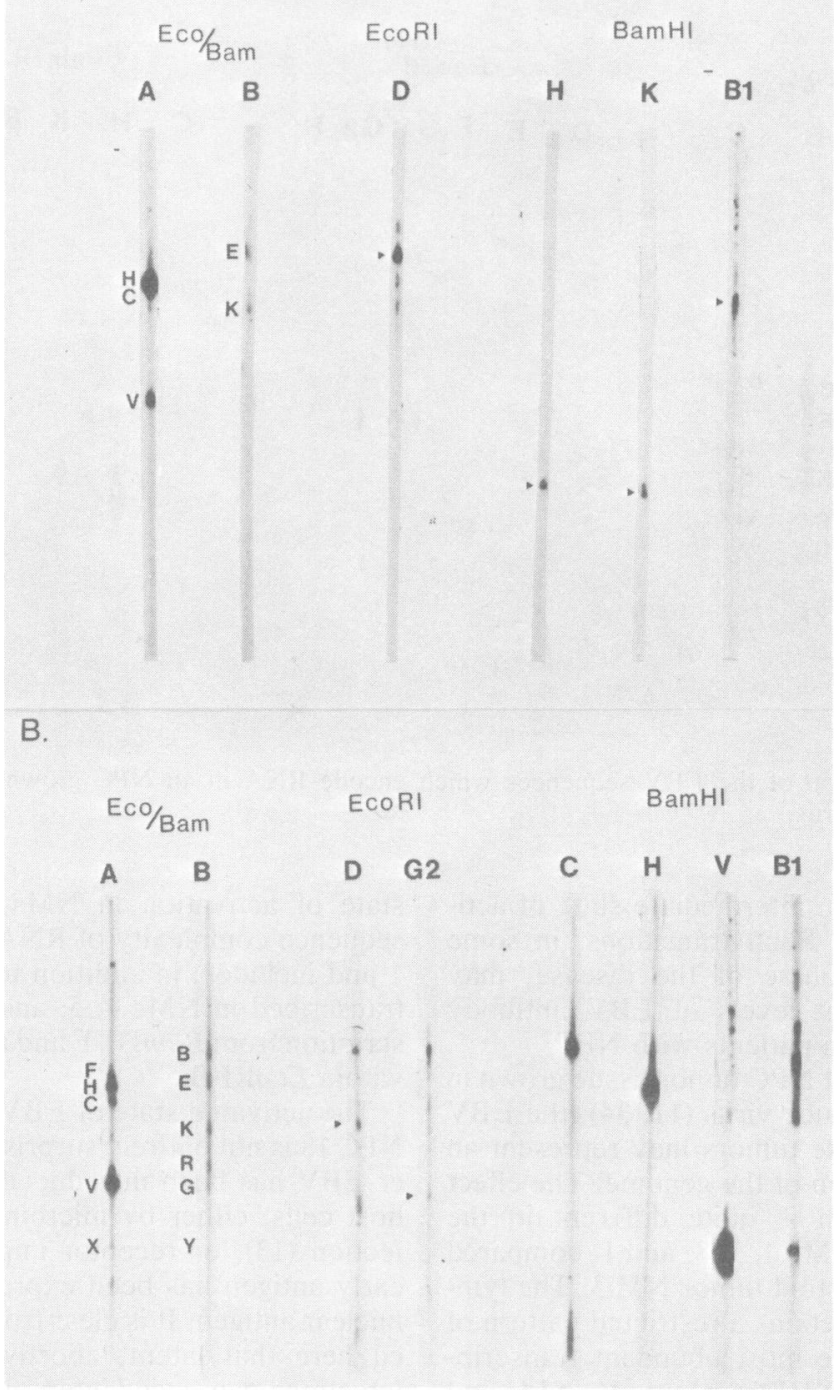

NM- 3

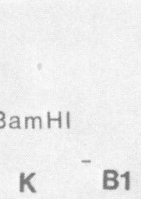


A.
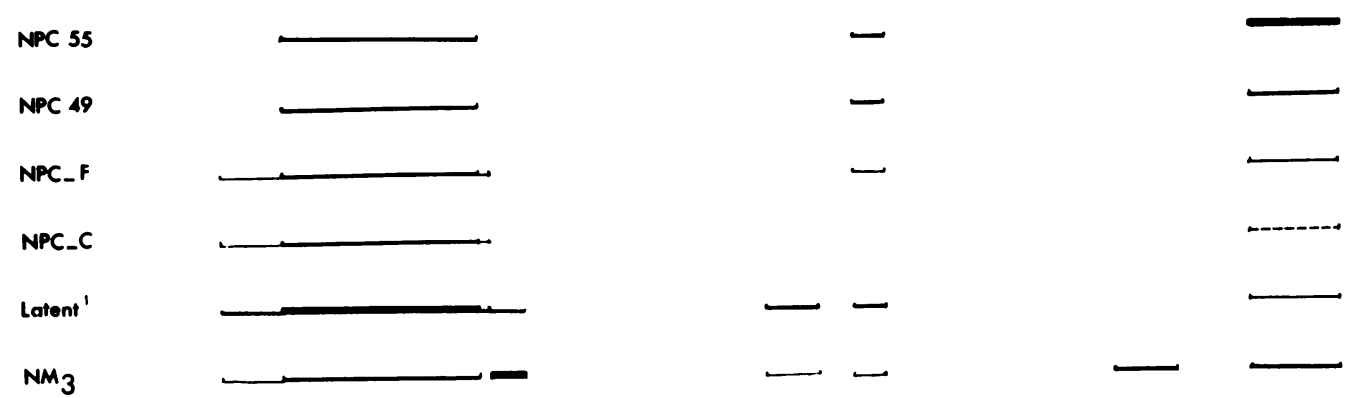

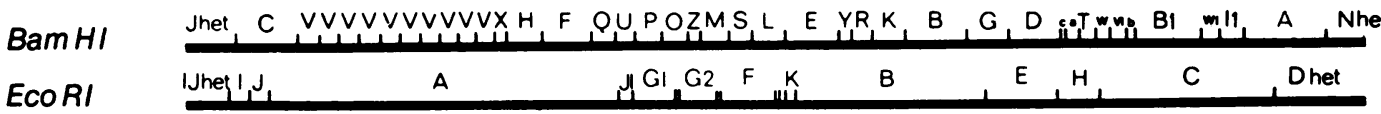

B.

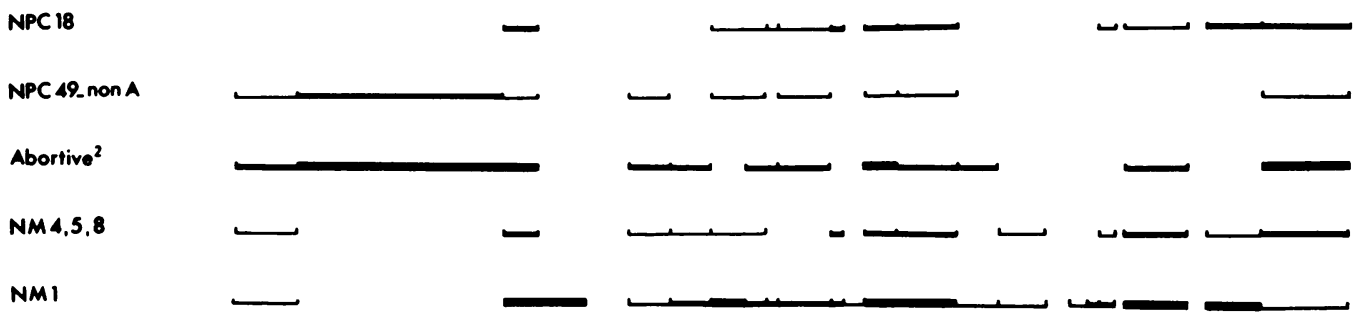

$\mathrm{BamHI}$

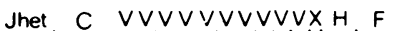

EcoRI

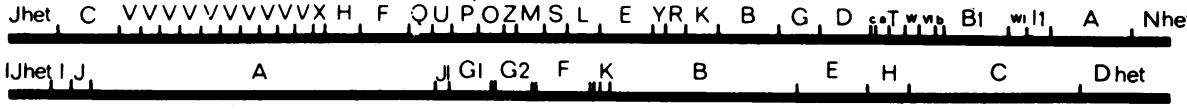

FIG. 7. Summary of EBV transcription in NPC. (A) Latent patterns of expression. Comparison of NPCs F, C, 49, and 55 and NM 3 to a latently EBV-infected lymphocyte line (23). (B) Activated patterns of expression. Comparison of the NPC 18 and NMs 4, 5, 8, and 1, to an induced EBV-infected lymphocyte line (24).

sequences which are transcribed in growthtransformed, latently infected lymphoblastoid cell lines are also transcribed in NPC tissue. However, it is also clear that other sequences can be transcribed and that at times the state of infection may be more analogous to an abortive infection. Based on the similar transcriptional patterns of the four tumors in this activated state, NPC 18 and NMs 4, 5, and 8, it is possible that particular functions are consistently expressed in such abortive infections in NPC tissue.

\section{ACKNOWLEDGMENTS}

This work was supported by National Institutes of Health Virus Program project 5-P01-CA-19014-06. N.R.T. is a Damon Runyon postdoctoral fellow (DR-405) and B.E.H. is a National Institutes of Health postdoctoral fellow (IFI32CA-0659801).

\section{LITERATURE CITED}

1. Aviv, H., and P. Leder. 1972. Purification of biologically active globin messenger RNA by chromatography on oligothymidylic acid-cellulose. Proc. Natl. Acad. Sci. U.S.A. 69:1408-1412.

2. Cheng, Y.-C., J.-Y. Chen, R. Glaser, and W. Henle. 1980. Frequency and levels of antibody to EBV-specific DNase are elevated in patients with NPC. Proc. Natl. Acad. Sci. U.S.A. 77:6162-6165.

3. Chirgwin, J. M., A. E. Przbyla, R. J. MacDonald, and W. J. Rutter. 1979. Isolation of biologically active ribonucleic acid from sources enriched in ribonuclease. Biochemistry 18:5294-5299.

4. Dambaugh, T., C. Beisel, M. Hummel, W. King, S. Fennewald, A. Cheung, M. Heller, N. Raab-Traub, and E. Kieff. 1980. Epstein-Barr virus (B95-8) DNA. VII. Molecular cloning and detailed mapping of EBV (B95-8) DNA Proc. Natl. Acad. Sci. U.S.A. 77:2999-3003.

5. Dambaugh, T., and E. Kieff. 1982. Identification and nucleotide sequences of two similar tandem direct repeats in Epstein-Barr virus DNA. J. Virol. 44:823-833.

6. Dambaugh, T., F. K. Nkrumah, R. J. Biggar, and E. Kieff. 
1979. Epstein-Barr virus RNA in Burkitt tumor tissue. Cell 16:313-322

7. Denhardt, D. T. 1966. A membrane-filter technique for the detection of complementary DNA. Biochem. Biophys. Res. Commun. 23:641-646.

8. de Thé, G. 1980. The role of the Epstein-Barr virus in human diseases: infectious mononucleosis (IM), Burkitt's lymphoma (BL), and nasopharyngeal carcinoma (NPC). p. 769-797. In G. Klein (ed.), Viral oncology. Raven Press, New York.

9. Feighny, R. J., B. E. Henry II, and J. S. Pagano. 1981 Epstein-Barr virus polypeptides: effects of inhibition of viral DNA replication on their synthesis. J. Virol. 37:6171.

10. Epstein, M. A., B. G. Achong, and Y. M. Barr. 1964. Virus particles in cultured lymphoblasts from Burkitt's lymphoma. Lancet 1:702-703.

11. Glaser, R., G. de Thé, G. Lenoir, and J. H. C. Ho. 1976. Superinfection of nasopharyngeal carcinoma epithelial tumor cells with Epstein-Barr virus. Proc. Natl. Acad. Sci. U.S.A. 73:960-963

12. Graessmann, A., H. Wolf, and G. W. Bornkamm. 1980. Expression of Epstein-Barr virus genes in different cell types after microinjection of viral DNA. Proc. Natl. Acad. Sci. U.S.A. 77:433-434.

13. Grogan, E., G. Miller, W. Henle, and J. C. Niederman. 1981. Expression of Epstein-Barr viral early antigen in monolayer tissue cultures after transfection with viral DNA and DNA fragments. J. Virol. 40:861-869.

14. Henle, G., and W. Henle. 1966. Immunofluorescence in cells derived from Burkitt's lymphoma. J. Bacteriol. 91:1248-1256.

15. Henle, G., and W. Henle. 1976. Epstein-Barr virus-specific IgA serum antibodies as an outstanding feature of nasopharyngeal carcinoma. Int. J. Cancer 17:1-7.

16. Henle, G., W. Henle, and V. Diehl. 1968. Relation of Burkitt tumor associated herpes-type virus to infectious mononucleosis. Proc. Natl. Acad. Sci. U.S.A. 59:94-101.

17. Henle, W., and G. Henle. 1979. Seroepidemiology of the virus, p. 62-78. In M. A. Epstein and B. G. Achpng_(ed $)_{6}$, The Epstein-Barr virus. Springer-Verlag, New York

18. Henle, W., G. Henle, B. A. Azjac, G. Pearson, R. Waubke, and M. Scriba. 1970. Differential reactivity of human serums with early antigens induced by Epstein-Barr virus. Science 169:188-190.

19. Henle, W., J. H. C. Ho, G. Henle, and H. C. Kwan. 1973. Antibodies to Epstein-Barr virus related antigens in nasopharyngeal carcinoma. Comparison to active cases and long term survivors. J. Natl. Cancer Inst. 51:361-369.

20. Hennessey, K., M. Heller, V. Van Santen, and E. Kieff. 1983. Simple repeat array in Epstein-Barr virus nuclear antigen. Science 220:1396-1398.

21. Hummel, M., and E. Kieff. 1982. Epstein-Barr virus RNA. VIII. Viral RNA in permissively infected B95-8 cells. J. Virol. 43:262-272.

22. Hummel, M., and E. Kieff. 1982. Mapping of polypeptides encoded by the Epstein-Barr virus genome in productive infection. Proc. Natl. Acad. Sci. U.S.A. 79:5698-5702

23. King, W., A. L. Thomas-Powell, N. Raab-Traub, M. Hawke, and E. Kieff. 1980. Epstein-Barr virus RNA. V. Viral RNA in a restringently infected, growth-transformed cell line. J. Virol. 36:506-518.

24. King, W., V. Van Santen, and E. Kieff. 1981. Epstein-Barr virus RNA. VI. Viral RNA in restringently and abortively infected Raji cells. J. Virol. 38:649-660.

25. Klein, G., B. C. Giovanella, T. Lindahl, P. J. Fialkow, S. Singh, and J. S. Stehlin. 1974. Direct evidence for the presence of Epstein-Barr virus DNA and nuclear antigen in malignant epithelial cells from patients with poorly differentiated carcinoma of the nasopharynx. Proc. Natl. Acad. Sci. U.S.A. 71:4737-4741

26. Raab-Traub, N., R. Pritchett, and E. Kieff. 1978. DNA of Epstein-Barr virus. III. Identification of restriction enzyme fragments that contain DNA sequences which differ among strains of Epstein-Barr virus. J. Virol. 27:388-398.

27. Raab-Traub, N., T. Dambaugh, and E. Kieff. 1980. DNA of Epstein-Barr virus. VIII. B95-8, the previous prototype, is an unusual deletion derivative. Cell 22:257-267.

28. Reedman, B. M., and G. Klein. 1973. Cellular localization of an Epstein-Barr virus (EBV) associated complementfixing antigen in producer and nonproducer lymphoblastoid cell lines. Int. J. Cancer 2:499-520.

29. Rigby, P. W. J., M. Dieckann, C. Rhodes, and P. Berg. 1977. Labeling deoxyribonucleic acid to high specific activity in vitro by nick translation with DNA polymerase. J. Mol. Biol. 113:237-251.

30. Seeburg, P. H., J. Shine, J. A. Martial, A. Ullrich, J. D. Baxter, and H. M. Goodman. 1977. Nucleotide sequence of part of the gene for human chorionic somatomammotropin: purification of DNA complementary to predominant mRNA species. Cell 12:157-165.

31. Southern, E. M. 1975. Detection of specific sequences among DNA fragments separated by gel electrophoresis. J. Mol. Biol. 98:502-517.

32. Summers, W. P., E. A. Grogan, D. Shedd, M. Robert, C. R. Liu, and G. Miller. 1982. Stable expression of nuclear neoantigen after transfer of a 3.4-megadalton cloned fragment of Epstein-Barr virus DNA. Proc. Natl. Acad. Sci. U.S.A. 79:5688-5692.

33. Taylor, J. M., R. Illmansee, and J. Summer. 1976. Efficient transcription of RNA into DNA by avian sarcoma virus polymerase. Biochem. Biophys. Acta 442:324-330.

34. Trumper, P. A., M. A. Epstein, and B. C. Giovanella. 1976. Activation in vitro by BUdR of a productive EB virus infection in the epithelial cells of nasopharyngeal carcinoma. Int. J. Cancer 17:578-587.

35. Van Santen, V., A. Cheung, and E. Kieff. 1981. EpsteinBarr virus RNA. VII. Size and direction of transcription of virus-specified cytoplasmic RNAs in a transformed cell line. Proc. Natl. Acad. Sci. U.S.A. 78:1930-1934.

36. Volsky, D. J., I. M. Shapiro, and G. Klein. 1980. Transfer of EBV receptors to receptor-negative cells permits virus penetration and antigen expression. Proc. Natl. Acad Sci. U.S.A. 77:5433-5457.

37. Weigel, R., and G. Miller. 1983. Major EB virus-specific cytoplasmic transcripts in a cellular clone of the HR-1 Burkitt lymphoma line during latency and after induction of viral replicative cycle by phorbol esters. Virology 125:287-298

38. Wolf, H., H. Zur Hausen, and Y. Becker. 1973. EB viral genomes in epithelial nasopoharyngeal carcinoma cells. Nature (London) New Biol. 244:245-257. 